Title: The ENSO-Australian rainfall teleconnection in reanalysis and CMIP5

Authors: Andrew D. King ${ }^{1}$, Markus G. Donat ${ }^{1}$, Lisa V. Alexander ${ }^{1}$, David J. Karoly ${ }^{2}$

Affiliations:

1. ARC Centre of Excellence for Climate System Science and Climate Change Research Centre, University of New South Wales, Sydney, NSW, Australia.

2. ARC Centre of Excellence for Climate System Science and School of Earth Sciences, University of Melbourne, Melbourne, VIC, Australia.

Corresponding Author:

Mr. Andrew D. King, Climate Change Research Centre, Level 4, Mathews Building, University of NSW, Sydney, NSW, Australia, 2052.

Email: andrew.king@student.unsw.edu.au

Keywords: Twentieth century reanalysis, precipitation, dynamics, thermodynamics, asymmetry, El Niño-Southern Oscillation 


\title{
The ENSO-Australian rainfall teleconnection in reanalysis and CMIP5
}

\author{
Andrew D. King, Markus G. Donat, Lisa V. Alexander, and David J. Karoly
}

\begin{abstract}
Australian rainfall is strongly influenced by the El Niño-Southern Oscillation (ENSO). The relationship between ENSO and rainfall in eastern Australia is non-linear; the magnitude of La Niña events has a greater effect on rainfall than does the magnitude of El Niño events, and the cause of the non-linearity is unclear from previous work. The twentieth century reanalysis succeeds in capturing the asymmetric ENSO-rainfall relationship. In the reanalysis the asymmetry is strongly related to moisture availability in the south-west Pacific whereas wind flow is of less importance. Some global climate models (GCMs) in the CMIP5 archive capture the asymmetric nature of the ENSO-rainfall relationship whilst others do not. Differences in thermodynamic processes and their relationships with ENSO are the primary cause of variability in model performance. Analysis of an atmosphere-only run of a GCM which fails to capture the non-linear ENSO-rainfall relationship is also conducted. The atmospheric run forced by observed SSTs shows no significant improvement in the ENSOrainfall relationship over the corresponding coupled model run in the CMIP5 archive. This result suggests that some models are failing to capture the atmospheric teleconnection between the tropical Pacific and Australia, and both this and a realistic representation of oceanic ENSO characteristics are required for coupled models to accurately capture the ENSO-rainfall teleconnection. These findings have implications for the study of rainfall projections in the region.
\end{abstract}

\section{Introduction}


Rainfall in eastern Australia is highly variable (Nicholls et al. 1997) and strongly related to the El Niño-Southern Oscillation (ENSO) (e.g. Risbey et al. 2009). In general, the La Niña (El Niño) phase of ENSO is associated with increased (decreased) rainfall over the east of Australia. Consequently, there is strong interannual variability in flood and drought risk associated with ENSO. Therefore, improving our understanding of the ENSO-Australian rainfall teleconnection would benefit the forecasting of, and planning for, extreme climatic events that impact many aspects of society and ecosystems.

The relationship between ENSO and East Australian rainfall is non-linear whereby the magnitude of a La Niña event has a greater effect on rainfall than the magnitude of an E1 Niño event does (Power et al. 2006; Cai et al. 2010; King et al. 2013a). The reasons for the non-linearity in the ENSO-rainfall relationship are not well understood (King et al. 2013b), however, the movement of the South Pacific Convergence Zone (SPCZ) has been presented as a possible mechanism (Cai and van Rensch 2012). Enhanced knowledge of the mechanisms behind the ENSO-rainfall asymmetry would also be beneficial in predicting and planning for droughts and floods.

Reanalysis data and climate model output may be useful in attempting to further our understanding of the ENSO teleconnection with Australian climate. The ability of global climate models (GCMs) to accurately represent aspects of ENSO is highly variable between models. Examining the most recent state-of-the-art climate models from the Fifth Coupled Model Intercomparison Project (CMIP5; Taylor et al. 2012), Bellenger et al. (2013) found some improvement in ENSO representation over older models. CMIP5 models perform well in capturing the locations of SST anomalies associated with ENSO and the relative amplitudes of El Niño and La Niña events; however, models struggle with other aspects of ENSO, such as seasonality of ENSO amplitude and the magnitude of different La Niña events (Taschetto et al. 2014). The SPCZ is a line of convergence, cloudiness and 
precipitation located to the northeast of Australia and a major atmospheric feature of the south-west Pacific linked with ENSO (Vincent et al. 2011). Properties of the SPCZ have been examined across the suite of CMIP5 models and some improvement over older climate models was also found (Brown et al. 2012). The ENSO-Australian rainfall relationship and its nonlinearity have not previously been studied using CMIP5.

Data from observational datasets, a long-running reanalysis product, and an ensemble of coupled atmosphere-ocean climate models were examined in this study as described in section 2. The results using reanalysis data (section 3.1), coupled climate models (section 3.2), and an atmosphere-only model (section 3.3) are presented. A discussion of the results is in section 4 and conclusions are given in section 5.

\section{Data and Methods}

The data used in this study are described separately for the observation-based datasets (2.1), the Twentieth Century reanalysis (2.2), and the CMIP5 suite of models (2.3). The indices calculated from these datasets and used as diagnostics in this analysis are also described (section 2.4). All analysis was performed for the October-March austral warm season when ENSO is at the peak of its cycle. Results are shown for warm seasons from 1900-2005 across observations, reanalysis, and CMIP5. All indices used in this study based on different variables were detrended by linear regression through the 1900-2005 period. Correlation coefficients are defined as significant at the $5 \%$ level.

\subsection{Gridded precipitation and SST observations}

The observed ENSO-rainfall relationship was examined initially. The Australian Water Availability Project (AWAP; Jones et al. 2009) dataset of gridded daily rainfall was used to calculate the East Australia area-average rainfall. AWAP has been shown to have reasonable 
representation of rainfall extremes where there is sufficient station density (King et al. 2013c). The AWAP dataset has an original resolution of $0.05^{\circ}$ and this was regridded to $0.5^{\circ}$.

Gridded observed SSTs from the HadISST dataset (Rayner et al. 2003) were also used for the calculation of indices representing ENSO and variability in local SSTs (as described in section 2.4).

\subsection{Twentieth Century reanalysis}

Data from the twentieth century reanalysis (20CR; Compo et al. 2011) were used as a proxy for the observed climate. This reanalysis product is constructed through the use of an atmosphere-only model constrained by SSTs, sea ice, and surface pressure observations from around the world. It is run from 1871 onwards and composed of a 56-member ensemble generated using an Ensemble Kalman filter data assimilation scheme. King et al. (2013b) found that the 20CR replicates the observed ENSO-extreme rainfall relationship reasonably well. Ensemble mean fields from the 20CR have been used in other studies of precipitation patterns in the region including studies of climate variability in southeast Australia (Ashcroft et al. 2013), rainfall variability in Queensland (Klingaman et al. 2013) and in Australia as a whole (King et al. submitted). Ensemble mean fields of monthly average precipitation, sea level pressure, zonal winds, and specific humidity are used in this study.

\subsection{CMIP5}

Model runs from state-of-the-art climate models were examined to compare the ENSOrainfall teleconnection with the relationships represented in the 20CR. Historical runs (run 1) from 35 models (listed in Table 1) in the CMIP5 archive were analysed. Monthly fields of surface temperature (ts), mean sea level pressure (psl), precipitation (pr), eastward winds (ua), and specific humidity (hus) were examined for each model run. 
2.4 Indices derived from observations, reanalysis and CMIP5

Indices based on various atmospheric and oceanic fields were calculated for the 20CR and CMIP5 models in order to investigate the ENSO-rainfall teleconnection in more detail. The fields from the 20CR and CMIP5 were interpolated on to a $2.5^{\circ}$ grid, so that results across the 20CR and models were more easily compared. All results presented are for 1900-2005 and the October-March warm seasons which is when ENSO is at the peak of its annual cycle and also a period when heavy rainfall in eastern Australia can often lead to severe flood events. Average values of each October-March period in the time series were analysed. The results presented are robust to the methods applied (i.e. tests using different time periods and interpolated/original grids showed no significant effects on results).

The Niño-3.4 index was calculated using gridded observed sea surface temperatures (SSTs) in the central Pacific region $\left(170^{\circ} \mathrm{W}\right.$ to $120^{\circ} \mathrm{W}$ and $5^{\circ} \mathrm{S}$ to $\left.5^{\circ} \mathrm{N}\right)$ from the HadISST dataset (Rayner et al. 2003). The model Niño-3.4 index was calculated over the same region using the surface temperature field from CMIP5. The sea level pressure fields were used to calculate a version of the Southern Oscillation Index (SOI) based on the pressure difference between gridboxes over Tahiti and Darwin in the 20CR and CMIP5.

An area-average rainfall index was computed for eastern Australia $\left(135^{\circ} \mathrm{E}\right.$ to $153^{\circ} \mathrm{E}$ and $10^{\circ} \mathrm{S}$ to $40^{\circ} \mathrm{S}$; shown as the boxed area in Fig. 1c) with a land-sea mask applied. The OctoberMarch total rainfall was calculated for each warm season from 1900-2005 for each gridbox within eastern Australia. These rainfall totals were then detrended. The rainfall total at each gridbox for each season was normalised to a percentage anomaly value relative to the mean total rainfall at individual gridboxes across all seasons. These normalised rainfall anomalies were then averaged across eastern Australia to represent warm season rainfall across the region. The rainfall values were normalised in AWAP, the 20CR, and CMIP5 models using 
the same method. This method does not weight the area-average index towards areas with greater rainfall totals, although results did not differ greatly if such a normalisation technique was not applied.

Several indices were calculated to examine the relative roles of local dynamic and thermodynamic processes in the ENSO-Australian rainfall relationship. To investigate the dynamic and thermodynamic influences in the lower troposphere (and above the surface) indices based on humidity and wind fields were calculated. The eastward wind field at 850 $\mathrm{hPa}$ was used to calculate a zonal wind index across a meridional line along $155^{\circ} \mathrm{E}$ from $15^{\circ} \mathrm{S}$ to $35^{\circ} \mathrm{S}$ (shown in Fig. 1c). The wind index was calculated as the average zonal wind along this meridian and reversed such that positive values imply onshore westward winds. The specific humidity at $850 \mathrm{hPa}$ was used to compute a moisture availability index as an average of the humidity along the same meridional line. The use of different meridional lines to the east of Australia (within $5^{\circ}-10^{\circ}$ of the continent) had little impact on the results.

Other indices were calculated based on sea surface temperatures in various regions around the Australian continent and also the width of the Southern Hemisphere Hadley circulation. Results using these diagnostics are not shown, but are discussed in section 4 .

The relationships between the ENSO indices and each of the (thermo-) dynamic indices were calculated through Spearman's rank correlations. The ENSO-rainfall relationship in the 20CR and each of the CMIP5 models was assessed through scatter plots of Niño-3.4 versus East Australia rainfall. The relative relationships of the various (thermo-) dynamic indices with rainfall were also examined through scatter plots. Maps of rank correlation coefficients between the (thermo-) dynamic indices and precipitation were plotted. The performance of the 20CR and CMIP5 models was evaluated through a range of measures of the asymmetric 
relationships between ENSO, the dynamic and thermodynamic indices, and rainfall in eastern Australia.

\section{Results}

3.1. The rainfall teleconnection in the twentieth century reanalysis

There is an observed asymmetric ENSO-Eastern Australia rainfall relationship (Fig. 1a). Rainfall totals are considerably greater during strong La Niña seasons than weak La Niña seasons, whereas the magnitude of El Niño is of less importance. The 20CR exhibits a similar asymmetric response of rainfall in eastern Australia to ENSO (Fig. 1b). A westward shift in the 20CR precipitation patterns for cooler central Pacific SSTs is shown in the mapped correlation coefficients between the Niño-3.4 index and rainfall (Fig. 1c,d). The magnitude of negative SST anomalies is strongly and significantly correlated with rainfall across eastern Australia (Fig. 1c), whereas the correlation coefficients in this region are non-significant if only positive SST anomalies are considered (Fig. 1d). The spatial patterns of these correlations in the 20CR over eastern Australia are similar to those in the AWAP gridded observational dataset (Fig. S1). As the 20CR replicates the observed ENSO-rainfall asymmetry, it may be used to study the teleconnection in more detail. To identify possible causes of the non-linear ENSO-rainfall relationship, scatter plots of indices based on 20CR fields of sea level pressure, zonal wind and specific humidity with rainfall were examined as well as correlation maps.

In the $20 \mathrm{CR}$, the $850 \mathrm{hPa}$ specific humidity index is strongly correlated to rainfall in eastern Australia and more so when Niño-3.4 SSTAs are negative than when SST anomalies are positive (Fig. 2). The scatter plots (Figs. 2a,b) point to a considerable asymmetry in the specific humidity-rainfall relationship dependent on the state of ENSO. The specific humidity index is well correlated with rainfall across inland areas of Queensland and New South Wales 
as well as along the coast, particularly in more La Niña-like seasons (Fig. 2c). In seasons when the Niño-3.4 index is positive the correlations are weaker, but remain significant closer to the coastline (Fig. 2d).

The relationship between wind at $850 \mathrm{hPa}$ and rainfall is considerably weaker than for the humidity index (Fig. 3). There is also a slight asymmetry in the $850 \mathrm{hPa}$ zonal wind relationship with rainfall as it is somewhat stronger when the Niño-3.4 index is negative than when it is positive. Zonal winds in the south-west Pacific are also significantly correlated with rainfall further south over the Tasman Sea and parts of the Southern Ocean (Fig. 3c).

There is also an asymmetry in the correlation of the Niño-3.4 index with the humidity index, but not for the wind index (see Table 2). The humidity index is well correlated with the Niño3.4 index when the Niño-3.4 index is negative $(-0.35)$ but not when it is positive $(-0.04)$. However, the wind index is only weakly correlated with the Niño-3.4 index with no strong signal for an asymmetry in the relationship.

These results suggest that in the 20CR there are contributions to the ENSO-rainfall asymmetric relationship from both dynamic and thermodynamic sources. However, moisture availability appears to play a greater role than the winds in this non-linear relationship (Figs. 2, 3). Thus, locally, thermodynamics seem to be of more importance than dynamics in determining the nature of the ENSO-rainfall relationship in eastern Australia.

\subsection{The rainfall teleconnection in CMIP5 models}

To examine the ENSO-East Australia rainfall relationship in more detail, output from a suite of 35 state-of-the-art climate models from the CMIP5 archive (see Table 1) was examined. Some variability in the nature of the ENSO-rainfall relationship was found between different models. All models studied had greater average rainfall totals in seasons of negative Niño-3.4 
index values (more La Niña-like) than when the Niño-3.4 index was positive (more El Niñolike), although for some models the difference was much greater than for others. Most, but not all, models also have at least a slight asymmetric relationship between ENSO and rainfall of a similar nature to that which is observed and in the 20CR. Examples of the ENSO-rainfall relationship in a model with a strong asymmetric relationship (BNU-ESM) and one with an asymmetry in a different direction to that observed (BCC-CSM1-1) are shown in Figure 4a,b. The correlation maps of the Niño-3.4 index with rainfall separated by ENSO phase show very different patterns for these two models. In seasons where the Niño-3.4 index is negative the correlation patterns are highly organised in BNU-ESM (Fig. 4c) and over larger spatial scales than in the 20CR (Fig. 1c). Significant negative correlations extend across Australia in BNUESM (Fig. 4c), whereas in BCC-CSM1-1 (Fig. 4d) the correlation patterns are less well organised and, generally, correlation coefficients are non-significant over eastern Australia. For seasons when the Niño-3.4 index is positive, the correlation coefficients between the Niño-3.4 index and precipitation are generally weaker over eastern Australia in BNU-ESM (Fig. 4e) and only remain significant over the north of the continent. The corresponding pattern in BCC-CSM1-1 (Fig. 4f) shows some significant correlations over eastern Australia, although the general pattern of correlation coefficients remains less organised than in BNUESM. These results emphasise the differences in the ENSO-rainfall relationship between some CMIP5 models. The causes for these differences were examined further.

\subsubsection{The thermodynamic relationships in CMIP5}

The specific humidity index was calculated for each CMIP5 model and relationships with rainfall and with ENSO were investigated. Examples of scatter plots of the specific humidity index against rainfall in different ENSO phases are again shown for BNU-ESM and BCCCSM1-1 (Fig. 5). In BNU-ESM there is a strong relationship between the humidity index and rainfall, particularly in seasons when the Niño-3.4 index is negative (Fig. 5a). This is not the 
case in BCC-CSM1-1 which has considerably weaker relationships between the humidity index and rainfall across both negative and positive (Fig. 5b) values of the Niño-3.4 index.

An intercomparison of the models was made using the regression slopes of the humidity index with rainfall plotted against the Niño-3.4 regression slope with rainfall based on negative Niño-3.4 index seasons (Fig. 6a). A relationship can be seen whereby models with larger humidity regression slopes with rainfall tend to have larger Niño-3.4 regression slopes with rainfall in more La Niña-like seasons (correlation of 0.33 , significant at $5 \%$ level). The corresponding relationship based on the difference between regression slopes in seasons of negative and positive Niño-3.4 values (i.e. representing the humidity-rainfall and ENSOrainfall asymmetries) is even stronger (correlation of 0.45 , significant at $1 \%$ level) (Fig. 6b). Hence, the magnitude of asymmetry in the humidity relationship with rainfall is strongly associated with the scale of asymmetry in the ENSO-rainfall relationship. None of the models have asymmetries in either relationship as strong as those seen in the 20CR (represented by the black circle in Fig. 6b).

Some models (14 of 35) reproduce the significant negative correlation between the Niño-3.4 index and humidity in more La Niña-like seasons (Table 2). Also, fewer models (7 of 35) have significant correlation coefficients between these indices in more El Niño-like periods. This suggests that moisture availability is a key component in the ENSO-rainfall teleconnection in several CMIP5 models as well as the 20CR.

\subsubsection{The dynamic relationships in CMIP5}

The dynamic role, represented by the zonal wind index, in the ENSO-rainfall relationship was investigated in CMIP5 in a similar manner to the thermodynamic role. Scatter plots of the wind index against rainfall separated into positive and negative values of the Niño-3.4 index were examined. Examples of these are again shown for BNU-ESM (Fig. 7a) and BCC- 
CSM1-1 (Fig. 7b). Similarly to the results with the humidity index (Fig. 5), stronger relationships between the wind index and rainfall are seen in BNU-ESM than in BCC-CSM11. Also, the relationship in BNU-ESM is stronger in seasons when the Niño-3.4 index is negative than when it is positive (Fig. 7a).

A model intercomparison of the relationships between wind index regression slopes with rainfall and ENSO regressions with rainfall in different states of ENSO was conducted. Weak relationships between the wind regression with rainfall and the Niño-3.4 regression with rainfall in seasons of negative Niño-3.4 values exist (Fig. 8a). Models with large regression slope values for wind with rainfall also tend to have larger regression slopes of the Niño-3.4 index with rainfall, although this relationship is non-significant (correlation of 0.22 ). A similar weak relationship (correlation of 0.25 ) can be seen using the difference between regression slopes based on the sign of the Niño-3.4 index (Fig. 8b).

Whilst the relationship between the Niño-3.4 index and winds to the east of Australia is weak in the 20CR, this is not the case for many CMIP5 models (Table 2). This suggests that for some models the ENSO-rainfall teleconnection is related to local dynamic processes which may not be the case in the real world.

Overall, these results point to both dynamic and thermodynamic relationships with the ENSO-rainfall asymmetry (or lack of asymmetry) in individual CMIP5 models. However, an intercomparison between CMIP5 models reveals a stronger thermodynamic relationship with the ENSO-rainfall asymmetry, whereas the dynamic relationship is weaker. As in the 20CR, the availability of atmospheric moisture is strongly associated with the nature of the ENSOrainfall relationship in CMIP5, and the relationship with the winds is weaker.

\subsection{The rainfall teleconnection in an atmosphere-only model}


The 20CR, essentially an atmosphere-only model constrained by SSTs, sea ice and surface pressure observations, captures the ENSO-rainfall asymmetry and many fully-coupled GCMs in the CMIP5 archive do not. This begs the question whether the constraints imposed by the SSTs or those due to the assimilation of surface pressure observations are of greater importance in the ability of models to capture the ENSO-rainfall relationship. Examining output from Atmospheric Model Intercomparison Project (AMIP)-style runs may help to answer this question. The AMIP runs of the majority of models in the CMIP5 archive only extend back to 1979 which is, unfortunately, not long enough to ascertain the nature of the ENSO-rainfall relationship. The observed ENSO-rainfall relationship between 1979 and 2005 is not asymmetric. This is a period when the Interdecadal Pacific Oscillation was generally in its positive (more El Niño-like) phase and therefore the ENSO-rainfall relationship is weaker (Cai and van Rensch 2012, King et al. 2013b). However, the GISS-E2-R AMIP run is considerably longer (1880-2010) and, therefore, may be used to examine the 1900-2005 period when the observed ENSO-rainfall relationship is non-linear (Fig. 1a). The fullycoupled GISS-E2-R historical run fails to capture the observed ENSO-rainfall asymmetry (Fig. 9a). The ENSO-rainfall relationship in the AMIP run of GISS-E2-R also fails to capture the observed ENSO-rainfall asymmetry for 1900-2005 (Fig. 9b). The weak relationship between the humidity index and rainfall in the AMIP run of GISS-E2-R is similar to the coupled run also (not shown). These results suggest that incorporating the correct SST forcing in a model is not sufficient for the teleconnection between ENSO and rainfall in Australia to be well-reproduced.

\section{Discussion}

The results presented here focus on the relationships of one dynamic index (based on $850 \mathrm{hPa}$ zonal wind) and one thermodynamic index (based on $850 \mathrm{hPa}$ specific humidity) with rainfall in eastern Australia and the associations of these indices with ENSO in reanalysis and climate 
models. Using these two indices it appears that the thermodynamic relationship with rainfall is stronger than that of the dynamics. However, other indices were also examined and these are not presented here. Indices based on SST anomalies local to eastern and northern Australia produced generally weak results. Relationships between SST anomalies and rainfall were limited to coastal areas of Queensland, and to a lesser degree New South Wales, with a lack of signal over inland regions. An index measuring the latitude of the western portion of the SPCZ (Vincent et al. 2011) was also examined; however, it produced relatively weak results and only a slight asymmetry in its relationship with rainfall. An index related to Hadley cell width, derived from the location of the ITCZ and sub-tropical ridge through the MSLP field over the Pacific Ocean, did not explain the ENSO-rainfall relationship either.

In this study, ENSO is defined through the Niño-3.4 index. Other oceanic indices could be used instead of the Niño-3.4 index to represent ENSO and to examine relationships between canonical and Modoki ENSO and East Australian rainfall. The Niño-3.4 index was selected here as it is a commonly used index for ENSO and the Niño-3.4-East Australian rainfall relationship exhibits the strong non-linearity which could then be studied.

The effect of atmosphere-ocean coupling on the ENSO-rainfall relationship was examined by considering the correlation between atmospheric and oceanic indices of ENSO, the SOI and Niño-3.4 index respectively. Scaife et al. (2009) found differing atmospheric responses to oceanic ENSO across a suite of atmosphere-only models. This would suggest that coupled models may display different atmospheric responses to oceanic ENSO and this could be the cause of the varying ENSO-rainfall relationships in CMIP5. Whilst there is a slight tendency for models with stronger SOI-Niño-3.4 correlations to better capture the ENSO-rainfall asymmetry, the relationship is not particularly strong (not shown). 
Analysis of a single AMIP historical run from 1900-2005 suggests that incorrect representation of the ENSO-rainfall teleconnection may be behind much of the poor performance of some CMIP5 models. The 20CR is constrained by in situ pressure observations as well as SSTs and performs better. Therefore, a realistic representation of atmospheric circulation may be of great importance in capturing the ENSO-Australian rainfall teleconnection. This also suggests that if a fully-coupled climate model reproduces observed characteristics of ENSO (such as amplitude, location, and timing) it will not necessarily also reproduce observed teleconnections with precipitation patterns. A model would very likely need both an accurate oceanic ENSO and a realistic atmospheric response in order to capture the ENSO-rainfall teleconnection well.

A fuller analysis with more AMIP runs extending over the twentieth century would increase the robustness of these findings; however, such data are not currently available. Similar AMIP-style experiments that extend further back, such as those from the Climate of the $20^{\text {th }}$ Century (C20C; Folland and Kinter 2002) experiment, are not based on models equivalent to those in the CMIP5 archive and are, therefore, of less use for this particular analysis.

Single runs from each model's historical simulations in the CMIP5 archive were examined. To establish the robustness of this study's results, analysis was performed on multiple runs of several models (CCSM4, CNRM-CM5, and HadGEM2-ES). Results across multiple runs of the same model were largely similar. Analysis of the ENSO-extreme rainfall asymmetric relationship based on maximum consecutive 5-day rainfall (as examined in King et al. 2013a, King et al. 2013b) using CMIP5 (Sillmann et al. 2013) gave less robust results in the asymmetry. Different runs of the same model had slightly more difference in ENSO-extreme rainfall relationships than in ENSO-mean rainfall relationships.

\section{Conclusions}


As is already well known, the relationship between ENSO and rainfall in eastern Australia is non-linear. The magnitude of negative SST anomalies in the Niño-3.4 region has a greater effect on precipitation in eastern Australia than the strength of positive values of the Niño-3.4 index has.

The twentieth century reanalysis captures the observed asymmetric ENSO-rainfall relationship. The asymmetry is more strongly related to thermodynamics than dynamics at least locally in the south-west Pacific. Moisture availability to the east of Australia is strongly correlated with ENSO magnitude in negative Niño-3.4 conditions but not when the index is positive, whereas wind correlations with the Niño-3.4 index are non-significant.

Most CMIP5 models have an asymmetric ENSO-rainfall relationship, although all are weaker than in the 20CR. Several models have slight asymmetric relationships in the opposite direction to the 20CR and observations. In models with stronger asymmetries in the ENSOrainfall relationship, moisture availability is significantly greater in La Niña seasons than in neutral and El Niño seasons. Models with weaker ENSO-rainfall relationships also have weaker relationships between humidity to the east of Australia and rainfall. Some individual CMIP5 models have relationships between zonal winds and the ENSO-rainfall asymmetry. Although, there is a non-significant relationship across the CMIP5 ensemble between the wind-rainfall relationship and the strength of the ENSO-rainfall asymmetry.

An AMIP run of a CMIP5 model that fails to capture the ENSO-rainfall asymmetry, also does not reproduce the observed relationship. Given that the 20CR does capture the asymmetric nature of the relationship, this points to the importance of a model being able to reproduce realistic atmospheric circulation as well as a realistic oceanic ENSO pattern. Realistic representation of oceanic ENSO is not sufficient for a model to capture the ENSOrainfall teleconnection in Australia (and possibly other regions of the world). 
This study has implications for the analysis of model projections of rainfall patterns under future greenhouse gas emissions scenarios. Many studies that examine climate projections are based on the mean of ensembles of models with variable performance (e.g. Alexander and Arblaster 2009). There is literature that finds the mean of a multi-model ensemble has higher skill than the single model with the most skill with applications across different aspects of the climate system (e.g. Doblas-Reyes et al. 2003; Donat et al. 2010), particularly when multiple diagnostics are combined (Hagedorn et al. 2005). However, for eastern Australia, and other areas under the strong influence of a particular climate driver, this may not be the case. Investigating how Australian rainfall projections are affected by variable model performance in capturing the ENSO-rainfall teleconnection could be of use in improving understanding of uncertainty in projections.

\section{Acknowledgments}

We thank Steve Woolnough and an anonymous reviewer for their useful feedback on this paper. We also thank Jaclyn Brown for useful discussions. Funding for this project was provided by Australian Research Council grant CE110001028. We thank the Bureau of Meteorology, the Bureau of Rural Sciences, and CSIRO for providing the Australian Water Availability Project data. $20^{\text {th }}$ Century Reanalysis data were provided by the NOAA/OAR/ESRL PSD, Boulder, Colorado, USA. Support for the Twentieth Century Reanalysis Project is provided by the U.S. Department of Energy, Office of Science Innovative and Novel Computational Impact on Theory and Experiment (DOE INCITE) program, and Office of Biological and Environmental Research (BER), and by the National Oceanic and Atmospheric Administration Climate Program Office. HadISST SSTs were provided by the U.K. Met Office. We also acknowledge the CMIP5 modelling groups.

\section{References}


Alexander LV, Arblaster JM (2009) Assessing trends in observed and modelled climate extremes over Australia in relation to future projections. Int J Climatol 29:417-435. doi: 10.1002/joc. 1730

Ashcroft L, Karoly DJ, Gergis J (2013) Southeastern Australian climate variability 18602009: a multivariate analysis. Int J Climatol doi: 10.1002/joc.3812

Bellenger H, Guilyardi E, Leloup J, Lengaigne M, Vialard J (2013) ENSO representation in climate models: from CMIP3 to CMIP5. Clim Dyn doi: 10.1007/s00382-013-1783-z

Brown JR, Moise AF, Colman RA (2012) The South Pacific Convergence Zone in CMIP5 simulations of historical and future climate. Clim Dyn doi: 10.1007/s00382-012-1591-x

Cai W, van Rensch P (2012) The 2011 southeast Queensland extreme summer rainfall: A confirmation of a negative Pacific Decadal Oscillation phase? Geophys Res Lett 39:L08702. doi:10.1029/2011GL050820

Cai W, van Rensch P, Cowan T, Sullivan A (2010) Asymmetry in ENSO Teleconnection with Regional Rainfall, Its Multidecadal Variability and Impact. J Clim 23:4944-4955.

Compo et al (2011) The twentieth century reanalysis project. Q J R Meteor Soc 137:1-28. doi: $10.1002 / \mathrm{qj} .776$

Doblas-Reyes FJ, Pavan V, Stephenson DB (2003) The skill of multi-model seasonal forecasts of the wintertime North Atlantic Oscillation. Clim Dyn 21:501-514. doi: $10.1007 / \mathrm{s} 00382-003-0350-4$

Donat MG, Leckebusch GC, Wild S, Ulbrich U (2010) Benefits and limitations of regional multi-model ensembles for storm loss estimations. Clim Res 44:211-225. doi: 10.3354/cr00891 
Folland C, Kinter III JL (2002) The Climate of the Twentieth Century Project. CLIVAR Exch 7(2):37-39.

Hagedorn R, Doblas-Reyes FJ, Palmer TN (2005) The rationale behind the success of multimodel ensembles in seasonal forecasting-1. Basic concept. Tellus A 57:219-233. doi: 10.1111/j.1600-0870.2005.00103.x

Jones DA, Wang W, Fawcett R (2009) High-quality spatial climate data-sets for Australia. Aust Meteor Ocean J 58:233-248.

King AD, Lewis SC, Perkins SE, Alexander LV, Donat MG, Karoly DJ, Black MT (2013a) Limited Evidence of Anthropogenic Influence on the 2011-12 Extreme Rainfall over Southeast Australia [in "Explaining Extreme Events of 2012 from a Climate Perspective"] Bull Am Meteor Soc 94(9):S55-S58.

King AD, Alexander LV, Donat MG (2013b) Asymmetry in the response of Eastern Australia extreme rainfall to low-frequency Pacific variability. Geophys Res Lett 40:22712277. doi: $10.1002 /$ grl.50427

King AD, Alexander LV, Donat MG (2013c) The efficacy of using gridded data to examine extreme rainfall characteristics: A case study for Australia. Int J Climatol 33:2376-2387. doi: 10.1002/joc. 3588

King AD, Klingaman NP, Alexander LV, Donat MG, Jourdain NC, Maher P (2014) Extreme rainfall variability in Australia: Patterns, drivers, and predictability. J Clim (submitted)

Klingaman NP, Woolnough SJ, Syktus J (2013) On the drivers of inter-annual and decadal rainfall variability in Queensland, Australia. Int J Climatol 33:2413-2430. doi: 10.1002/joc. 3593 
Nicholls N, Drosdowsky W, Lavery B (1997) Australian rainfall variability and change. Weather 52:66-71.

Power S, Haylock M, Colman R, Wang X (2006) The Predictability of Interdecadal Changes in ENSO Activity and ENSO Teleconnections. J Clim 19:4755-4771.

Rayner NA, Parker DE, Horton EB, Folland CK, Alexander LV, Rowell DP, Kent EC, Kaplan A (2003) Global analyses of sea surface temperature, sea ice, and night marine air temperature since the late nineteenth century. J Geophys Res (Atmos) 108:4407. doi:10.1029/2002JD002670

Risbey JS, Pook MJ, McIntosh PC, Wheeler MC, Hendon HH (2009) On the Remote Drivers of Rainfall Variability in Australia. Mon Weather Rev 137:3233-3253.

Scaife et al (2009) The CLIVAR C20C project: selected twentieth century climate events. Clim Dyn 33:603-614. doi: 10.1007/s00382-008-0451-1

Sillmann J, Kharin VV, Zhang X, Zwiers FW, Bronaugh D (2013) Climate extremes indices in the CMIP5 multimodel ensemble: Part 1. Model evaluation in the present climate. $\mathrm{J}$ Geophys Res (Atmos) 118:1716-1733. doi: 10.1002/jgrd.50203

Taschetto AS, Sen Gupta A, Jourdain NC, Santoso A, Ummenhofer CC, England MH (2014) Cold tongue and warm pool ENSO events in CMIP5: mean state and future projections. $\mathbf{J}$ Clim 27:2861-2885. doi: 10.1175/JCLI-D-13-00437.1

Taylor KE, Stouffer RJ, Meehl GA (2012) An Overview of CMIP5 and the experiment design. Bull Am Meteorol Soc 93:485-498. doi: 10.1175/BAMS-D-11-00094.1 
Vincent EM, Lengaigne M, Menkes CE, Jourdain NC, Marchesiello P, Madec G (2011) Interannual variability of the South Pacific Convergence Zone and implications for tropical cyclone genesis. Clim Dyn 36:1881-1896. doi: 10.1007/s00382-009-0716-3

\section{Figure Captions}

Figure 1: (a-b) Scatter plots of the October-March Niño-3.4 index from HadISST against OctoberMarch area-average East Australia rainfall totals in (a) AWAP gridded rainfall observations and (b) the 20CR ensemble-mean precipitation. Lines of best fit, regression slopes, Spearman's rank correlations and p-values are shown for negative (red) and positive (blue) values of the Niño-3.4 index. (c-d) Maps of correlation coefficients between the Oct-Mar Niño-3.4 index and precipitation in the 20CR in (c) seasons where the Niño-3.4 index is negative only and (d) seasons where the Niño-3.4 index is positive only. Stippling indicates Spearman's rank correlations significant at the 5\% level. (c) The area within the white box is defined as East Australia in this study. The white line is the meridian used in the calculation of the specific humidity and zonal wind indices.

Figure 2: (a-b) Scatter plots of the Oct-Mar specific humidity index against E. Australia area-average rainfall in (a) seasons where the Niño-3.4 index is negative only and (b) seasons where the Niño-3.4 index is positive only. Lines of best fit, regression slopes, Spearman's rank correlations and p-values are shown. (c-d) Maps of correlation coefficients between the Oct-Mar specific humidity index and precipitation in the 20CR in (c) seasons where the Niño-3.4 index is negative only and (d) seasons where the Niño-3.4 index is positive only. Stippling indicates Spearman's rank correlations significant at the $5 \%$ level. 
Figure 3: (a-b) Scatter plots of the Oct-Mar zonal wind index against E. Australia area-average rainfall in (a) seasons where the Niño-3.4 index is negative only and (b) seasons where the Niño-3.4 index is positive only. Lines of best fit, regression slopes, Spearman's rank correlations and p-values are shown. (c-d) Maps of correlation coefficients between the Oct-Mar zonal wind index and precipitation in the 20CR in (c) seasons where the Niño-3.4 index is negative only and (d) seasons where the Niño-3.4 index is positive only. Stippling indicates Spearman's rank correlations significant at the $5 \%$ level.

Figure 4: (a-b) Scatter plots of the October-March Niño-3.4 index against October-March areaaverage East Australia rainfall in (a) BNU-ESM and (b) BCC-CSM1-1. Lines of best fit, regression slopes, Spearman's rank correlations and p-values are shown for negative (red) and positive (blue) values of the Niño-3.4 index. (c-f) Maps of correlation coefficients between the Oct-Mar Niño-3.4 index and precipitation in (c,d) seasons where the Niño-3.4 index is negative only and (e,f) seasons where the Niño-3.4 index is positive only for BNU-ESM and BCC-CSM1-1 respectively. Stippling indicates Spearman's rank correlations significant at the 5\% level.

Figure 5: (a,b) Scatter plots of the Oct-Mar specific humidity index against E. Australia area-average rainfall in seasons where the Niño-3.4 index is negative only (red diamonds) and seasons where the Niño-3.4 index is positive only (blue diamonds) in (a) BNU-ESM and (b) BCC-CSM1-1. Lines of best fit, regression slopes, Spearman's rank correlations and p-values are shown for negative (red) and positive (blue) values of the Niño-3.4 index.

Figure 6: Scatter plots of 20CR (black circle) and CMIP5 models (coloured numbers- see Table 1): (a) humidity index regression slope in seasons where Niño-3.4 index is negative only versus Niño-3.4 regression slope on to E. Australia rainfall in seasons where Niño-3.4 index is negative only, and (b) 
the difference in humidity index regression slopes between seasons where Niño-3.4 index is negative only and Niño-3.4 index is positive only versus the difference in Niño-3.4 regression slopes on to E. Australia rainfall in seasons where Niño-3.4 index is negative only minus Niño-3.4 index is positive only.

Figure 7: (a,b) Scatter plots of the Oct-Mar zonal wind index against E. Australia area-average rainfall in seasons where the Niño-3.4 index is negative only (red diamonds) and seasons where the Niño-3.4 index is positive only (blue diamonds) in (a) BNU-ESM and (b) BCC-CSM1-1. Lines of best fit, regression slopes, Spearman's rank correlations and p-values are shown for negative (red) and positive (blue) values of the Niño-3.4 index.

Figure 8: Scatter plots of 20CR (black circle) and CMIP5 models (coloured numbers- see Table 1): (a) wind index regression slope in seasons where Niño-3.4 index is negative only versus Niño-3.4 regression slope on to E. Australia rainfall in seasons where Niño-3.4 index is negative only, and (b) the difference in wind index regression slopes between seasons where Niño-3.4 index is negative only and Niño-3.4 index is positive only versus the difference in Niño-3.4 regression slopes on to E. Australia rainfall in seasons where Niño-3.4 index is negative only minus Niño-3.4 index is positive only.

Figure 9: Scatter plots of the October-March Niño-3.4 index against October-March area-average East Australia rainfall in (a) the CMIP5 run of GISS-E2-R for 1900-2005 and (b) the AMIP run of GISSE2-R (diamonds) and AWAP gridded observations (crosses) for 1900-2005. Lines of best fit are shown for negative (red) and positive (blue) values of the Niño-3.4 index for GISS-E2-R (solid) and AWAP (dashed). In (a) the regression slopes, Spearman's rank correlations and p-values are shown for negative (red) and positive (blue) values of the Niño-3.4 index respectively. 
Figure S1: (a-b) Maps of Spearman's rank correlation coefficients between the Oct-Mar Niño-3.4 index and precipitation in AWAP in (a) seasons where the Niño-3.4 index is negative only and (b) seasons where the Niño-3.4 index is positive only. Stippling indicates correlations significant at the $5 \%$ level.

\section{The ENSO-Australian rainfall teleconnection in reanalysis and CMIP5: Tables}

Andrew D. King, Markus G. Donat, Lisa V. Alexander, and David J. Karoly

Table 1: Details of the CMIP5 models which were analysed in this study.

\begin{tabular}{|c|c|c|}
\hline Model Number & Model & Symbol in Figures 6,8 \\
\hline 1 & ACCESS1-0 & Blue '1' \\
\hline 2 & ACCESS1-3 & Blue '2' \\
\hline 3 & bcc-csm1-1 & Blue ' 3 ' \\
\hline 4 & bcc-csm1-1-m & Blue '4' \\
\hline 5 & BNU-ESM & Blue '5' \\
\hline 6 & CanESM2 & Blue ' 6 ' \\
\hline 7 & CCSM4 & Blue ' 7 ' \\
\hline 8 & CESM1-BGC & Blue ' 8 ' \\
\hline 9 & CESM1-CAM5 & Blue '9' \\
\hline 10 & CESM1-FASTCHEM & Blue '0' \\
\hline 11 & CNRM-CM5 & Green ' 1 ' \\
\hline 12 & CNRM-CM5-2 & Green '2' \\
\hline 13 & FIO-ESM & Green ' 3 ' \\
\hline 14 & GFDL-CM2p1 & Green '4' \\
\hline 15 & GFDL-CM3 & Green '5' \\
\hline 16 & GFDL-ESM2G & Green ' 6 ' \\
\hline 17 & GISS-E2-H-CC & Green ' 7 ' \\
\hline
\end{tabular}




\begin{tabular}{|c|c|c|}
\hline 18 & GISS-E2-H & Green ' 8 ' \\
\hline 19 & GISS-E2-R-CC & Green '9' \\
\hline 20 & GISS-E2-R & Green ' 0 ' \\
\hline 21 & HadGEM2-AO & Orange ' 1 ' \\
\hline 22 & HadGEM2-CC & Orange '2' \\
\hline 23 & HadGEM2-ES & Orange ' 3 ' \\
\hline 24 & IPSL-CM5A-LR & Orange '4' \\
\hline 25 & IPSL-CM5A-MR & Orange ' 5 ' \\
\hline 26 & IPSL-CM5B-LR & Orange ' 6 ' \\
\hline 27 & MIROC-ESM-CHEM & Orange ' 7 ' \\
\hline 28 & MIROC-ESM & Orange ' 8 ' \\
\hline 29 & MIROC5 & Orange '9' \\
\hline 30 & MPI-ESM-MR & Orange '0' \\
\hline 31 & MPI-ESM-P & Red ' 1 ' \\
\hline 32 & MRI-ESM1 & Red '2' \\
\hline 33 & MRI-CGCM3 & Red '3' \\
\hline 34 & NorESM1-ME & Red '4' \\
\hline 35 & NorESM1-M & Red '5' \\
\hline
\end{tabular}

Table 2: Correlation coefficients (Spearman's rank) between the Niño-3.4 index and the humidity and wind indices for positive and negative values of the Niño-3.4 index separately in the 20CR and CMIP5. The zonal wind index is defined as positive for westward flow. Correlation coefficients significant at the 5\% level are shown in bold.

\begin{tabular}{|l|l|l|l|l|}
\hline & Moisture availability, & Moisture & Zonal wind, & Zonal wind, \\
& negative Niño-3.4 & availability, & negative Niño- & positive Niño- \\
& positive Niño-3.4 & 3.4 & 3.4 \\
\hline
\end{tabular}




\begin{tabular}{|c|c|c|c|c|}
\hline 20CR & -0.35 & -0.04 & 0.15 & 0.18 \\
\hline ACCESS1-0 & -0.44 & 0.03 & -0.24 & -0.05 \\
\hline ACCESS1-3 & -0.18 & -0.12 & -0.06 & 0.13 \\
\hline BCC-CSM1-1 & -0.17 & -0.11 & 0.30 & -0.22 \\
\hline BCC-CSM1-1-M & -0.25 & 0.01 & 0.03 & -0.16 \\
\hline BNU-ESM & -0.51 & -0.25 & -0.49 & -0.14 \\
\hline CanESM2 & -0.07 & -0.26 & -0.10 & -0.24 \\
\hline CCSM4 & -0.26 & -0.11 & -0.19 & 0.05 \\
\hline CESM1-BGC & -0.21 & -0.07 & -0.02 & 0.24 \\
\hline CESM1-CAM5 & -0.41 & -0.13 & 0.10 & 0.26 \\
\hline $\begin{array}{l}\text { CESM1- } \\
\text { FASTCHEM }\end{array}$ & -0.39 & -0.15 & 0.15 & 0.24 \\
\hline CNRM-CM5 & -0.47 & -0.14 & -0.15 & -0.21 \\
\hline CNRM-CM5-2 & -0.34 & 0.08 & 0.16 & -0.13 \\
\hline FIO-ESM & -0.34 & -0.35 & -0.42 & -0.30 \\
\hline GFDL-CM2p1 & -0.30 & 0.10 & 0.13 & -0.50 \\
\hline GFDL-CM3 & -0.07 & -0.28 & -0.08 & -0.31 \\
\hline GFDL-ESM2G & -0.34 & -0.37 & 0.04 & -0.01 \\
\hline GISS-E2-H & -0.15 & -0.02 & -0.01 & -0.31 \\
\hline GISS-E2-H-CC & -0.06 & -0.25 & -0.19 & -0.27 \\
\hline GISS-E2-R & -0.20 & 0.18 & -0.11 & 0.06 \\
\hline GISS-E2-R-CC & -0.25 & -0.01 & -0.32 & 0.05 \\
\hline HadGEM2-AO & -0.08 & -0.07 & 0.02 & -0.05 \\
\hline HadGEM2-CC & -0.40 & -0.04 & -0.39 & 0.09 \\
\hline HadGEM2-ES & -0.29 & -0.11 & 0.01 & 0.05 \\
\hline IPSL-CM5A-LR & -0.35 & 0.06 & -0.27 & -0.09 \\
\hline IPSL-CM5A-MR & -0.15 & -0.10 & -0.34 & -0.15 \\
\hline
\end{tabular}




\begin{tabular}{|l|l|l|l|l|}
\hline IPSL-CM5B-LR & -0.01 & 0.25 & 0.02 & 0.13 \\
\hline MIROC5 & -0.16 & -0.04 & $\mathbf{- 0 . 2 6}$ & -0.26 \\
\hline MIROC-ESM & -0.11 & $\mathbf{- 0 . 3 7}$ & -0.15 & -0.13 \\
\hline MIROC-ESM- & -0.18 & -0.20 & -0.23 & -0.05 \\
CHEM & & & & \\
\hline MPI-ESM-MR & $\mathbf{- 0 . 3 7}$ & -0.17 & $\mathbf{- 0 . 3 0}$ & -0.18 \\
\hline MPI-ESM-P & -0.13 & $\mathbf{- 0 . 3 0}$ & $\mathbf{- 0 . 3 5}$ & $\mathbf{- 0 . 1 6}$ \\
\hline MRI-CGCM3 & 0.06 & -0.13 & -0.01 & 0.01 \\
\hline MRI-ESM1 & -0.11 & $\mathbf{0 . 3 0}$ & -0.09 & -0.03 \\
\hline NorESM1-M & $\mathbf{- 0 . 3 2}$ & $\mathbf{- 0 . 3 3}$ & $\mathbf{0 . 2 8}$ & 0.08 \\
\hline NorESM1-ME & -0.13 & -0.03 & 0.03 & 0.18 \\
\hline
\end{tabular}


Normalized Rainfall (\%)
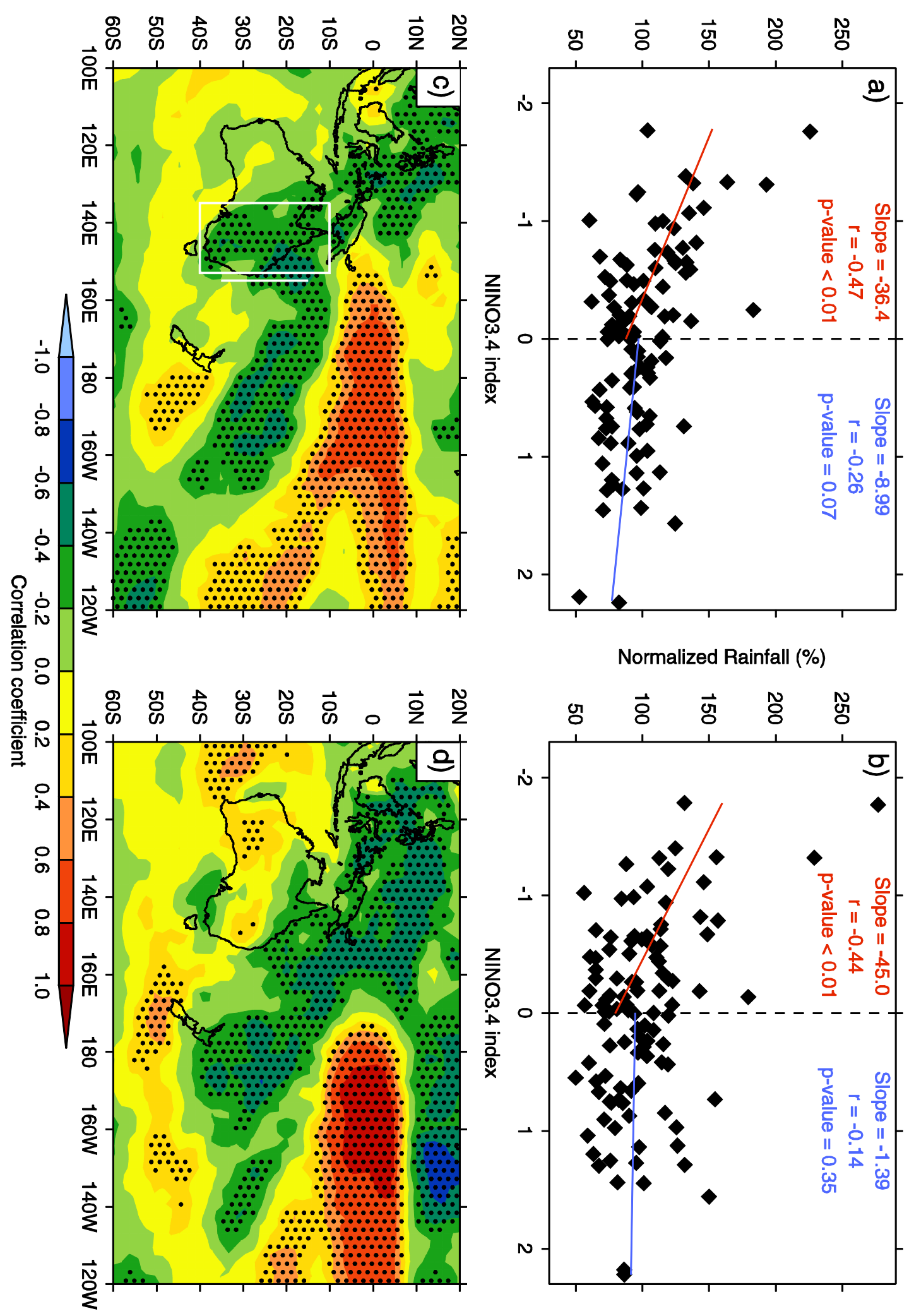

Normalized Rainfall (\%)

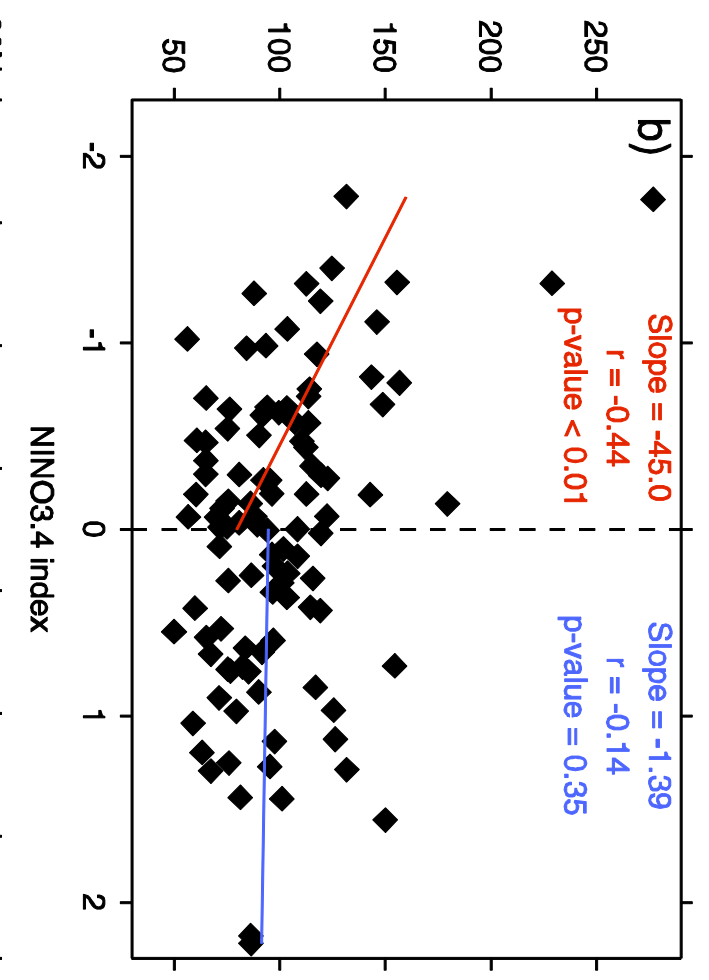

Figure 1 
Normalized Rainfall (\%)

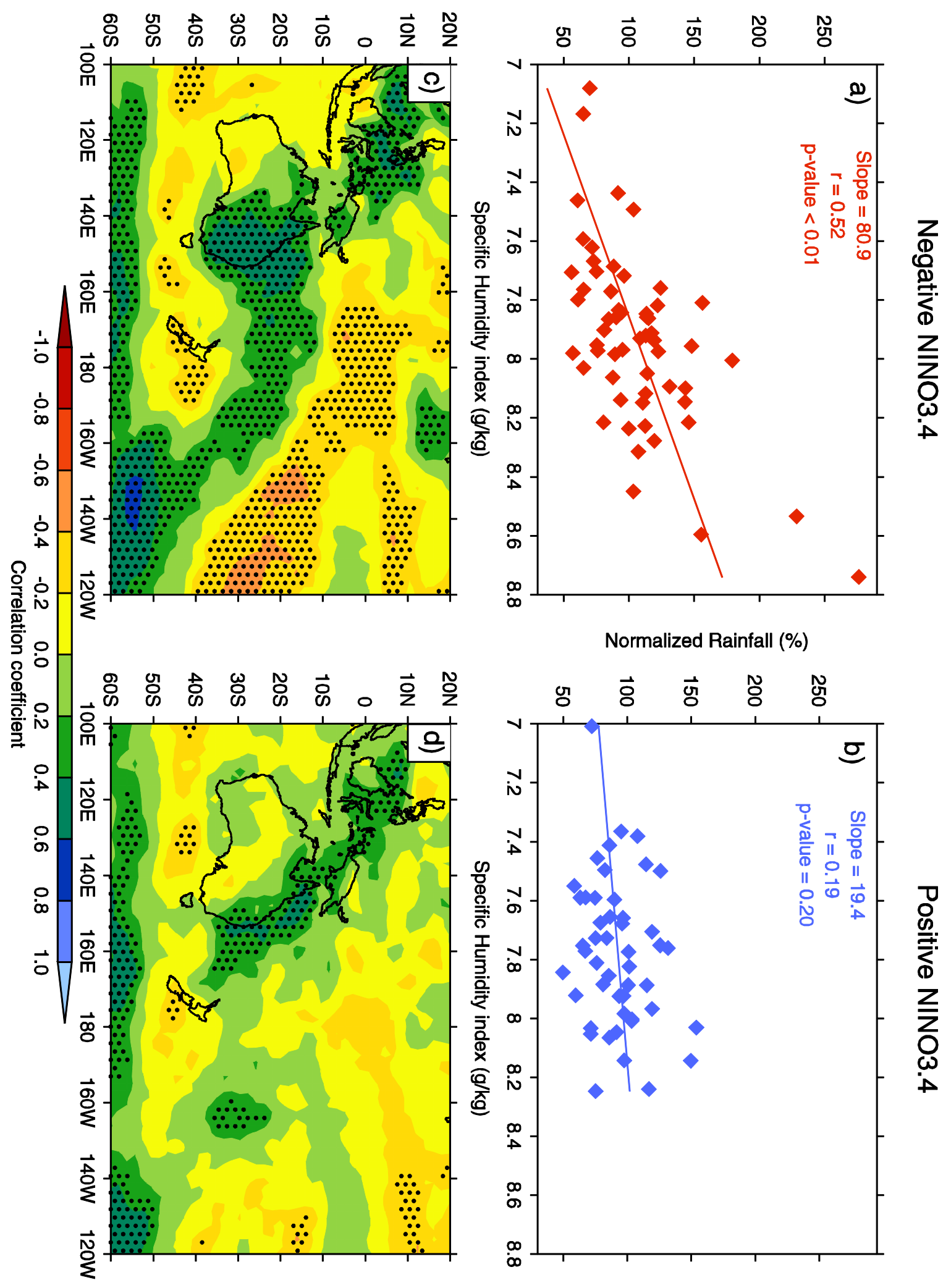


Figure 2 


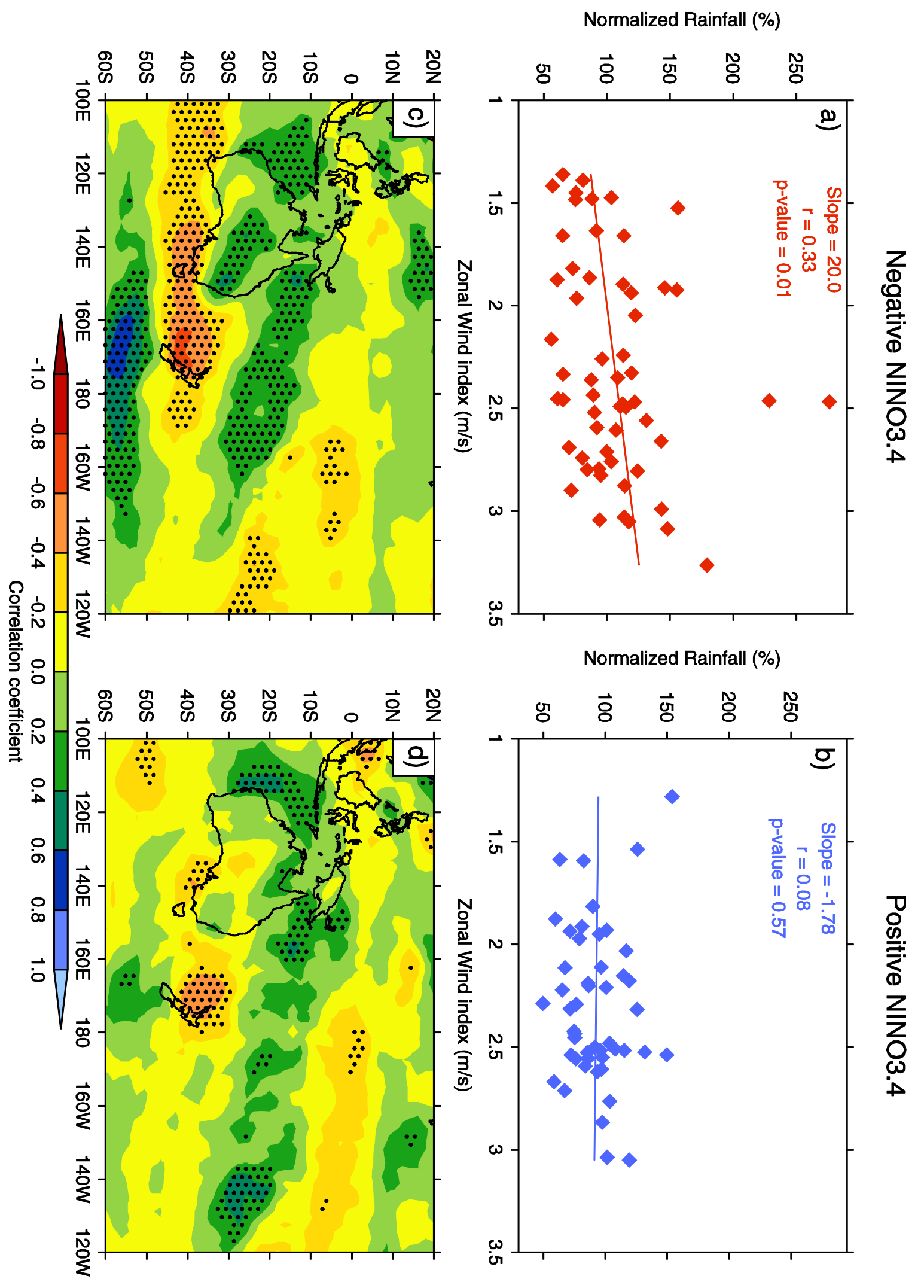

Figure 3 
Normalized Rainfall (\%)
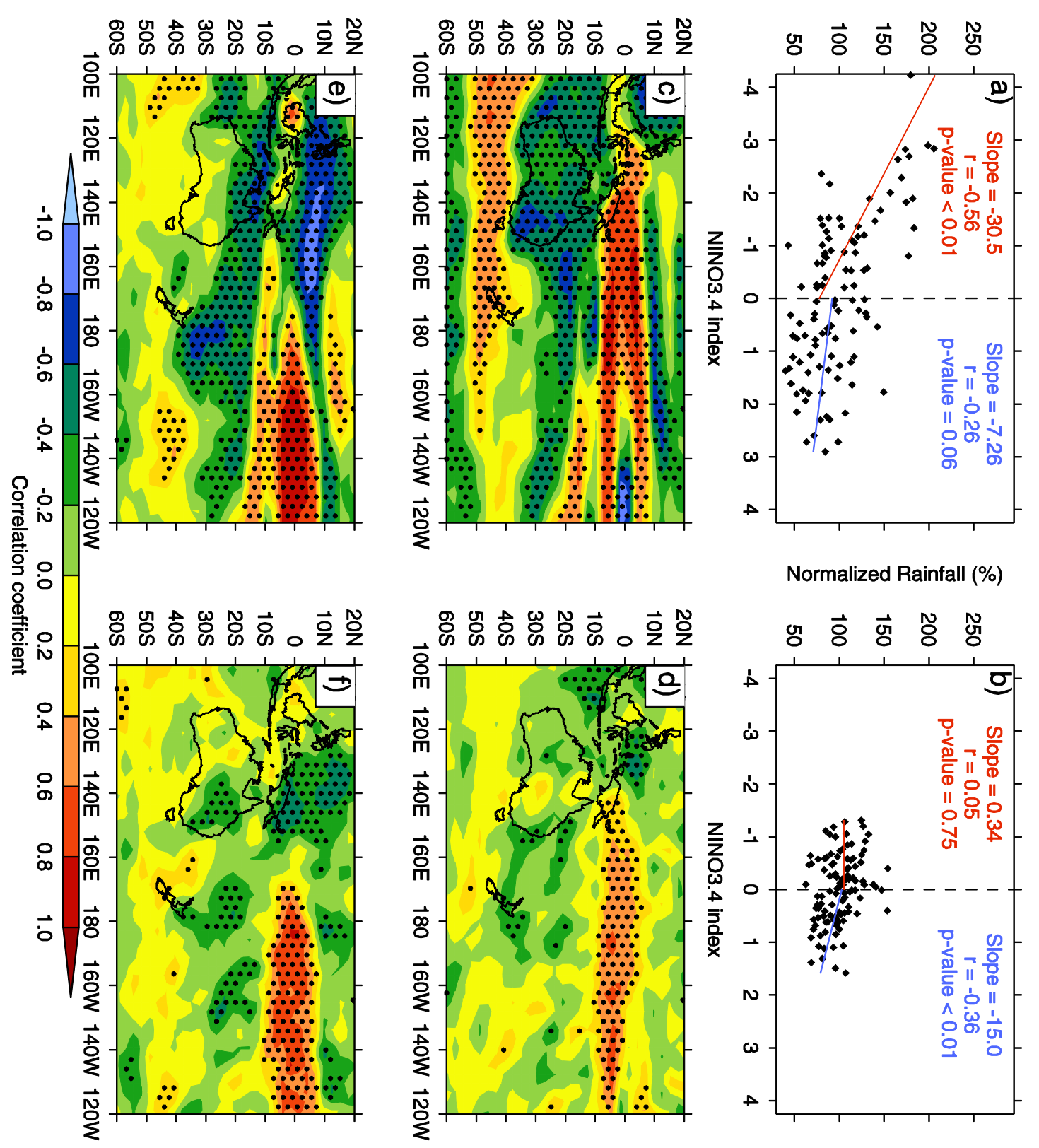
Figure 4 
Normalized Rainfall (\%)
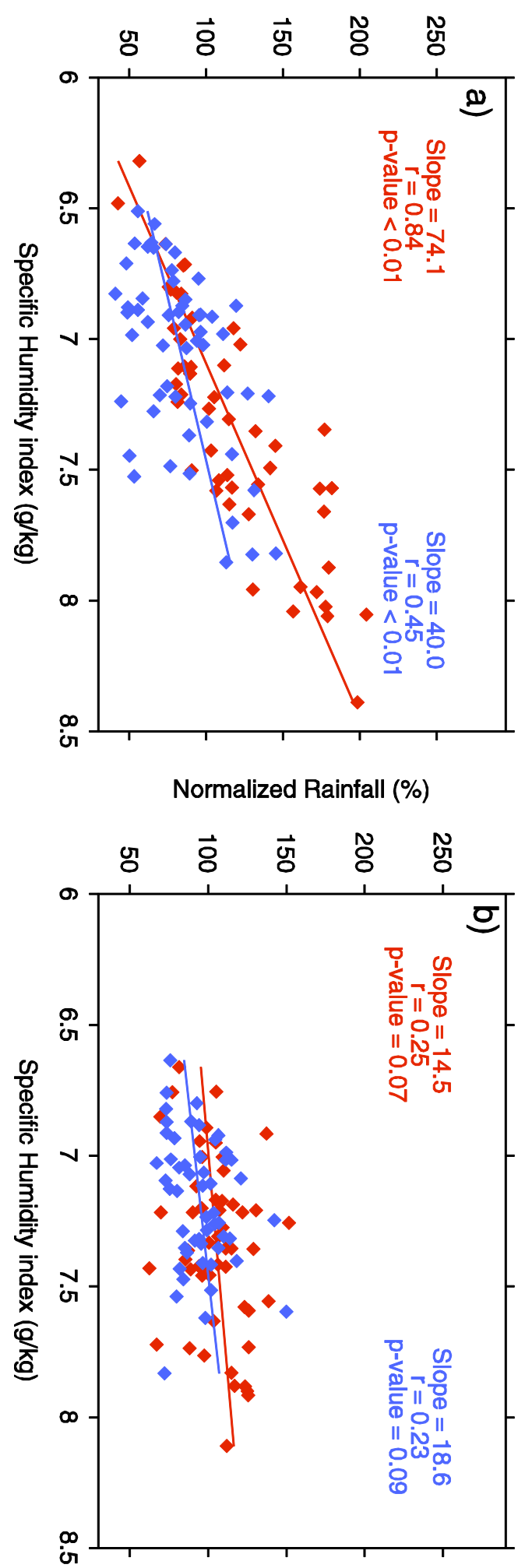

Figure 5 


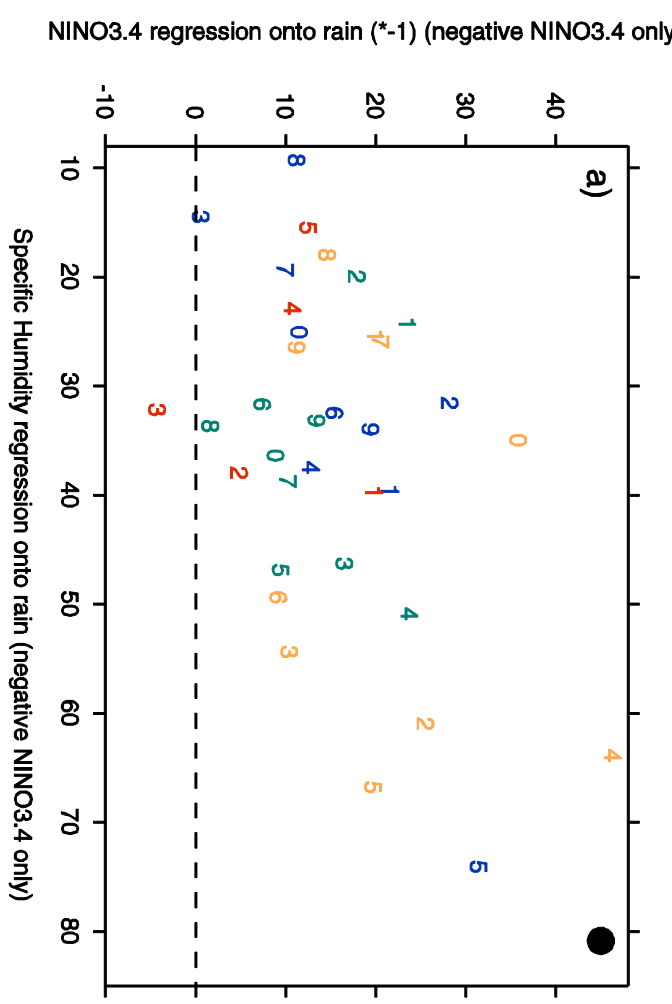

NINO3.4 regression onto rain $\left({ }^{*}-1\right)$ (negative - positive NINO3.4)

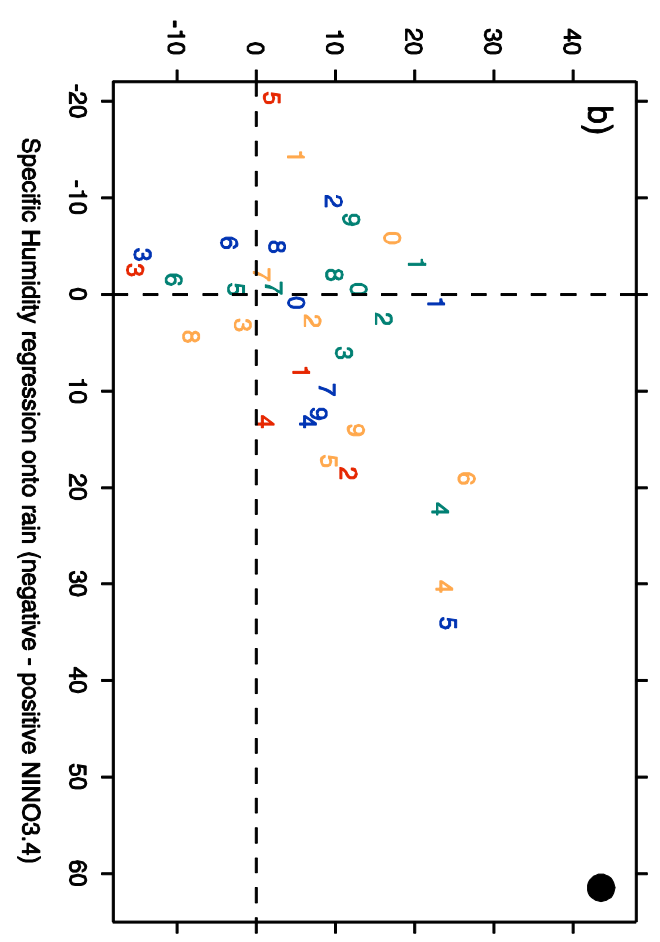


Figure 6 
Normalized Rainfall (\%)

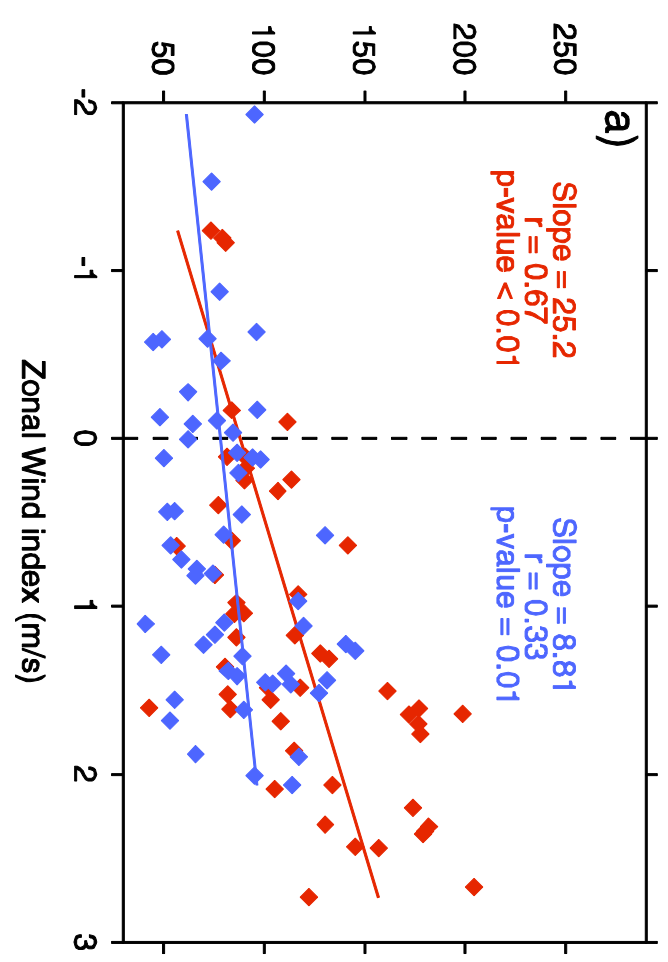

Normalized Rainfall (\%)

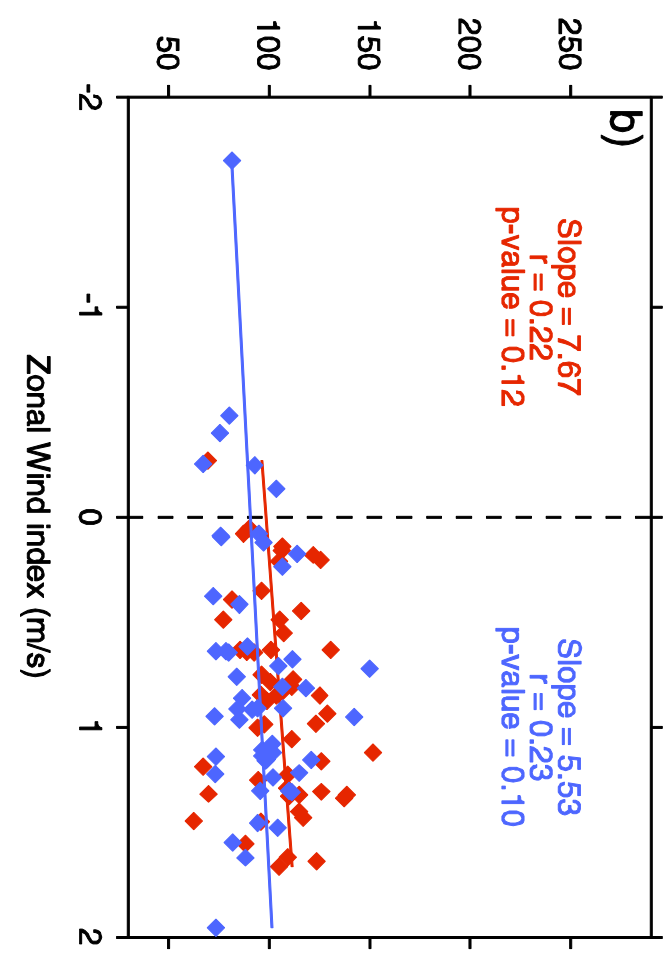

Figure 7 


\section{NINO3.4 regression onto rain $\left({ }^{*}-1\right)$ (negative NINO3.4 only)}

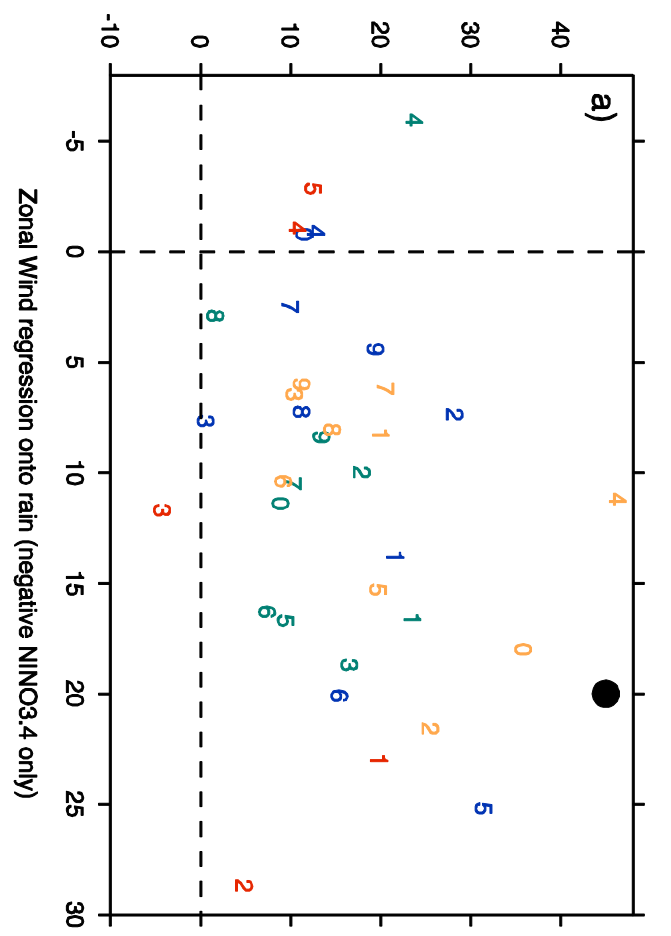

NINO3.4 regression onto rain $\left({ }^{*}-1\right)$ (negative - positive NINO3.4)

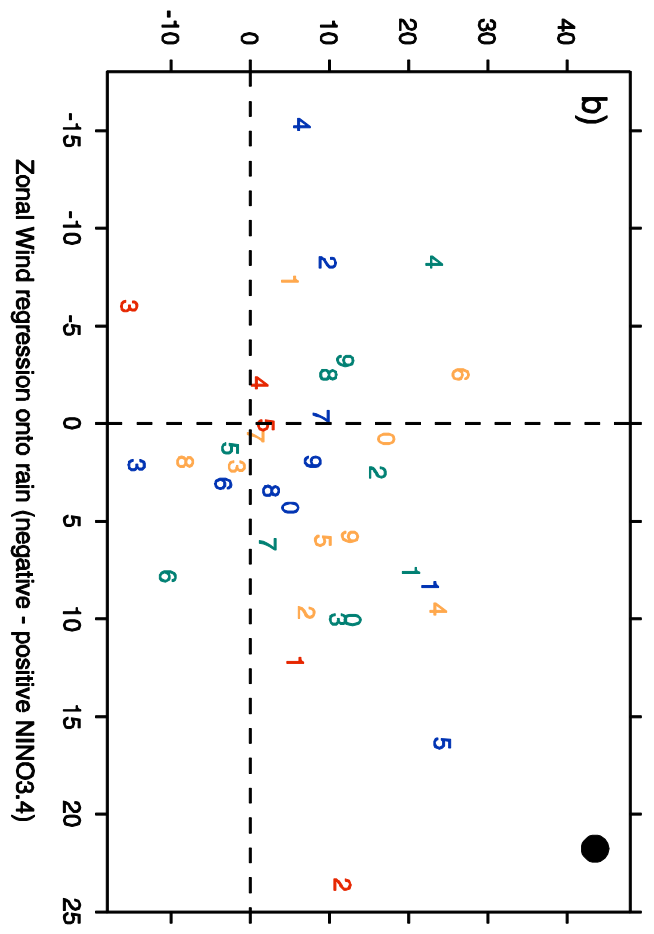


Figure 8 

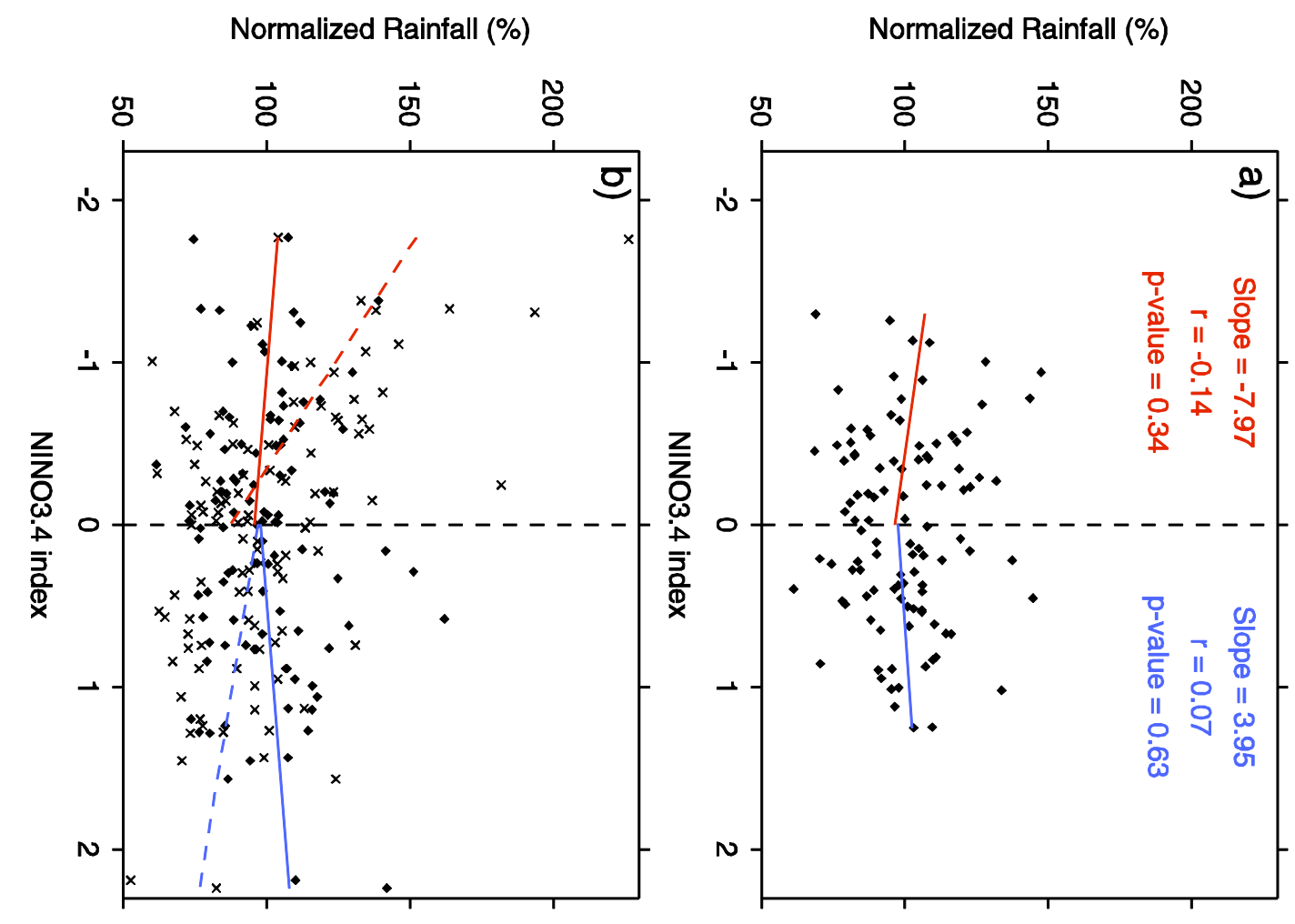

Figure 9 
